\title{
Towards a unified protocol for handling of CSF before $\beta$-amyloid measurements
}

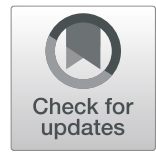

Shorena Janelidze ${ }^{1 *}$, Erik Stomrud ${ }^{1,2}$, Britta Brix $^{3}$ and Oskar Hansson ${ }^{1,2^{*}}$

\begin{abstract}
Background: Widespread implementation of Alzheimer's disease biomarkers in routine clinical practice requires the establishment of standard operating procedures for pre-analytical handling of cerebrospinal fluid (CSF).

Methods: Here, CSF collection and storage protocols were optimized for measurements of $\beta$-amyloid (A $\beta)$. We investigated the effects of (1) storage temperature, (2) storage time, (3) centrifugation, (4) sample mixing, (5) blood contamination, and (6) collection gradient on CSF levels of A 3 . For each study participant, we used fresh CSF directly collected into a protein low binding (LoB) tube that was analyzed within hours after lumbar puncture (LP) as standard of truth. $A \beta 42$ and $A \beta 40$ were measured in de-identified CSF samples using EUROIMMUN and Mesoscale discovery assays.
\end{abstract}

Results: CSF A $\beta 42$ and $A \beta 40$ were stable for at least $72 \mathrm{~h}$ at room temperature (RT), 1 week at $4{ }^{\circ} \mathrm{C}$, and 2 weeks at $-20^{\circ} \mathrm{C}$ and $-80^{\circ} \mathrm{C}$. Centrifugation of non-blood-contaminated CSF or mixing of samples before the analysis did not affect $A \beta$ levels. Addition of $0.1-10 \%$ blood to CSF that was stored at RT without centrifugation led to a doseand time-dependent decrease in $A \beta 42$ and $A \beta 40$, while $A \beta 42 / A \beta 40$ did not change. The effects of blood contamination were mitigated by centrifugation and/or storage at $4^{\circ} \mathrm{C}$ or $-20^{\circ} \mathrm{C}$. A $\beta$ levels did not differ between the first to fourth 5 -ml portions of CSF.

Conclusions: CSF can be stored for up to $72 \mathrm{~h}$ at RT, 1 week at $4{ }^{\circ} \mathrm{C}$, or at least 2 weeks at either $-20^{\circ} \mathrm{C}$ or $-80^{\circ} \mathrm{C}$ before $A \beta$ measurements. Centrifugation of fresh non-blood-contaminated CSF after LP, or mixing before analysis, is not required. In case of visible blood contamination, centrifugation and storage at $4{ }^{\circ} \mathrm{C}$ or $-20^{\circ} \mathrm{C}$ is recommended. After discarding the first $2 \mathrm{ml}$, any portion of up to $20 \mathrm{ml}$ of CSF is suitable for A $\beta$ analysis. These findings will be important for the development of a clinical routine protocol for pre-analytical handling of CSF.

Keywords: Cerebrospinal fluid, Biomarkers, Pre-analytical variables, Alzheimer's disease diagnosis, $\beta$-Amyloid

\section{Background}

Cerebrospinal fluid (CSF) Alzheimer's disease (AD) biomarkers, $\beta$-amyloid 42 (A $\beta 42)$ and tau, have been incorporated into the clinical research criteria for $\mathrm{AD}$ diagnosis proposed by the US National Institute on Aging-Alzheimer's Association (NIA-AA) [1] and International Working Group (IWG) for New Research Criteria for the Diagnosis of AD [2] However, to be able to implement CSF AD biomarkers worldwide, we need to have (i) appropriate use criteria in place, (ii) high precision methods to determine CSF AD biomarker levels with very low within and between laboratory variations,

\footnotetext{
* Correspondence: shorena.janelidze@med.lu.se; Oskar.Hansson@med.lu.se ${ }^{1}$ Department of Clinical Sciences Malmö, Clinical Memory Research Unit, Lund University, Sölvegatan 19, BMC B11, 22184 Lund, Sweden Full list of author information is available at the end of the article
}

and (iii) a unified pre-analytical protocol for handling of CSF before analyses. Recently, the Alzheimer's Association multidisciplinary workgroup released criteria for the appropriate use of lumbar puncture (LP) and CSF testing in the diagnosis of $\mathrm{AD}$ to facilitate decision-making by healthcare practitioners [3]. Further, several commercially available immunoassays measuring CSF AD biomarkers have been optimized resulting in very high precision for the determination of $\mathrm{AD}$ biomarkers $[4,5]$. Ongoing effort to produce certified reference materials [6] and recent development of a certified mass spectrometry (MS)-based reference measurement procedure for $A \beta 42$ [7] have already harmonized biomarker data obtained using different assays. At the same time, a significant proportion of the variability in reported $A D$

(c) The Author(s). 2019 Open Access This article is distributed under the terms of the Creative Commons Attribution 4.0 International License (http://creativecommons.org/licenses/by/4.0/), which permits unrestricted use, distribution, and 
biomarker levels between centers is due to the differences in pre-analytical procedures, and therefore, the standardization of biomarker measurements and establishment of global cutoffs will critically depend on the development of a unified pre-analytical protocol. Previous investigations have shown that multiple pre-analytical factors may influence CSF levels of AD biomarkers [8]. For example, differences in collection tube types, storage temperature, and duration; handling of bloodcontaminated samples; centrifugation steps; and the number of freeze-thaw cycles may introduce more than $50 \%$ change in CSF A $\beta 42$ concentrations [8-11]. However, previous studies were confined to the analysis of samples that were stored frozen after collection and thus lack a proper standard of truth, i.e., fresh CSF obtained directly in protein low binding (LoB) tubes and analyzed after LP without any pre-analytical steps in-between collection and analyses. Further, a protocol developed for use in clinical practice needs to be as simple as possible to facilitate implementation worldwide.

The aim of the present study was to study the effects of different pre-analytical handling procedures using fresh CSF analyzed within hours after LP as the standard of truth, paving the way for a unified pre-analytical protocol for clinical routine use. We chose to focus on CSF $A \beta$ measurements, because earlier findings suggest that amyloid peptides, $A \beta 42$ and $A \beta 40$, are particularly sensitive to pre-analytical handling whereas tau is less affected [12-15]. We investigated how pre-analytical factors (including storage at different temperatures and for different periods of time, centrifugation, mixing of samples before $A \beta$ analysis, and blood contamination) influence CSF levels of $A \beta 42$ and $A \beta 40$. To limit potential effects of analytical variables, $A \beta 42$ and $A \beta 40$ were measured using 2 different immunoassays, EUROIMMUN (EI) and Mesoscale discovery (MSD).

\section{Materials and methods CSF collection}

De-identified CSF samples from a total of 59 patients were used in this study. Patients were undergoing LP as a part of the Swedish BioFINDER Study or due to clinical suspicion of normal pressure hydrocephalus at the Memory Clinic, Skåne University Hospital, Sweden. All patients gave their written informed consent allowing their CSF samples to be used for research. Previous studies have shown that compared to polypropylene, LoB material significantly reduces $A \beta 42$ loss due to adsorption to plastic $[11,16]$. Therefore, LoB tubes were used for CSF collection. In all pre-analytical protocols, after discarding the first $2 \mathrm{ml}, 0.5-0.75 \mathrm{ml}$ of CSF was dripped from a LP needle directly into 1.5-ml LoB tubes (Sarstedt, Nümbrecht, Germany, catalog number 72.703.600). The number of tubes per each study participant and the treatment and analysis of CSF samples in different pre-analytical protocols are described below.

\section{Pre-analytical protocols \\ CSF storage at different temperatures}

Room temperature and $4{ }^{\circ} \mathrm{C}$ CSF was collected from 12 patients ( 3 patients per day, 10 CSF tubes per patient). From all 12 participants, all 10 CSF samples were analyzed within hours (h) after LP (baseline; for flowchart, please see Additional file 1: Figure S1A). After baseline analysis, 5 CSF tubes from each patient were stored refrigerated at $4{ }^{\circ} \mathrm{C}$ and the other 5 tubes at room temperature (RT; $19-23^{\circ} \mathrm{C}$ ). Two CSF samples from each patient ( 1 tube that had been stored at RT and the other stored at $4{ }^{\circ} \mathrm{C}$ ) were analyzed at $24 \mathrm{~h}, 48 \mathrm{~h}, 72 \mathrm{~h}, 1$ week, or 2 weeks after collection. CSF from each tube was analyzed twice, i.e., at baseline and at one of the five different time points, $24 \mathrm{~h}, 48 \mathrm{~h}, 72 \mathrm{~h}, 1$ week, and 2 weeks after collection. These non-frozen CSF samples were not centrifuged after LP. CSF $A \beta 42$ and $A \beta 40$ were measured using EI and MSD kits.

$-20^{\circ} \mathrm{C}$ and $-80^{\circ} \mathrm{C}$ CSF was collected from other $10 \mathrm{pa}$ tients (6 and 4 patients per day, 4 CSF tubes per patient). From all 10 participants, all 4 CSF samples were analyzed at baseline (Additional file 1: Figure S1B). After baseline analysis, 2 CSF tubes from each patient were stored at $-20^{\circ} \mathrm{C}$ and the other 2 tubes at $-80^{\circ} \mathrm{C}$. All 4 CSF samples from each patient ( 2 tubes stored at $-20^{\circ} \mathrm{C}$ and the other 2 tubes stored at $-80^{\circ} \mathrm{C}$ ) were analyzed 2 weeks after collection. Frozen samples were thawed at $\mathrm{RT}$ and mixed for $15 \mathrm{~min}$ using a roller mixer immediately before the analysis except for few CSF samples that were analyzed without mixing (Additional file 1: Figure S1B). CSF was not centrifuged after LP. Fresh CSF samples were not mixed before the analysis. CSF $\mathrm{A} \beta 42$ and $\mathrm{A} \beta 40$ were measured using EI and MSD kits.

\section{Mixing of CSF before the analysis}

CSF was collected from 6 patients (3 patients per day, 4 CSF tubes per patient). From all 6 participants, all 4 CSF samples were analyzed at baseline (Additional file 1: Figure S2). After baseline analysis, 2 CSF tubes from each patient were stored at RT and the other 2 CSF tubes at $4{ }^{\circ} \mathrm{C}$. Two CSF samples from each patient ( 1 tube stored at RT and the other stored at $4{ }^{\circ} \mathrm{C}$ ) were mixed for $15 \mathrm{~min}$ using a roller mixer immediately before the analysis; the other 2 CSF samples were analyzed without mixing. In addition to baseline, CSF samples from all 4 tubes were analyzed at $24 \mathrm{~h}, 48 \mathrm{~h}, 72 \mathrm{~h}, 1$ week, and 2 weeks after collection. CSF was not centrifuged after LP. CSF A 42 and A $\beta 40$ were measured using EI and MSD kits. 


\section{Blood contamination and centrifugation}

In the initial experiments (Additional file 1: Figure S3), we studied the effects of blood contamination. CSF was collected from 4 patients (2 patients per day, 12 CSF tubes per patient). For all 4 patients, blood was drawn into serum BD Vacutainer $^{\circ}$ tubes (Becton Dickinson AB, Stockholm, Sweden) and added to 8 CSF tubes from the same individual (final volume $0.1 \%$ [ 4 CSF tubes] or $10 \%$ [4 CSF tubes]) immediately after CSF collection, whereas the remaining 4 tubes contained neat CSF (see Additional file 1: Figure S4 for photographs of blood-contaminated CSF samples). Blood contamination at $0.1 \%$ and $10 \%$ corresponds to approximately 5000 and 500000 erythrocytes per microliter $(\mathrm{E} / \mu \mathrm{l})$, respectively. A total of 6 tubes per patient $(2$ neat CSF tubes, 2 CSF-0.1\%-blood tubes, and 2 CSF-10\%-blood tubes) were centrifuged within $2 \mathrm{~h}$ after collection $(2000 g$, $10 \mathrm{~min}$ ). The other 6 tubes ( 2 neat CSF tubes, 2 CSF-0.1\%blood tubes, and 2 CSF-10\%-blood tubes) were not centrifuged. From all 4 participants, all 12 CSF tubes were analyzed on the day of collection. After analysis, CSF and CSF-blood samples (centrifuged and non-centrifuged) were stored at either RT or $4^{\circ}$; one tube of neat CSF, CSF-0.1\%blood, and CSF-10\%-blood were used per each four conditions: (i) no centrifugation and storage at RT, (ii) no centrifugation and storage at $4{ }^{\circ} \mathrm{C}$, (iii) centrifugation and storage at RT, and (iv) centrifugation and storage at $4{ }^{\circ} \mathrm{C}$ (Additional file 1: Figure S3). In addition to baseline, CSF samples from all 12 tubes were analyzed at 1 week and 2 weeks after collection. Samples were mixed for $15 \mathrm{~min}$ using a roller mixer immediately before the analysis. CSF A $\beta 42$ were measured using EI kits.

In the second set of experiments, we studied the effects of blood contamination in more detail. The protocol was the same as for the initial experiment (Additional file 1: Figure S3) with the following modifications. CSF was collected from 7 to 10 patients (1-2 patients per day, 24 CSF tubes per patient) per experimental condition, and we added $1 \%$ blood contamination (final volume $0.1 \%, 1 \%$, or $10 \%$, Additional file 1 : Figure S4) and storage at $-20^{\circ} \mathrm{C}$. For $-20^{\circ} \mathrm{C}$, all CSF samples were analyzed at baseline and 2 weeks after collection. Two CSF tubes were used per each condition (centrifugation, blood contamination, and temperature) with all samples and analysis shown in Additional file 1: Figure S5. CSF $A \beta 42$ and $A \beta 40$ were measured using MSD kits.

Finally, we assessed the effect of blood contamination at very low levels on CSF A $\beta$ levels. We used CSF samples with $0.01 \%, 0.02 \%$, and $0.04 \%$ blood which corresponds to approximately $500 \mathrm{E} / \mu \mathrm{l}, 1000 \mathrm{E} / \mu \mathrm{l}$, and 2000 $\mathrm{E} / \mu \mathrm{l}$, respectively (see Additional file 1: Figure S4 for photographs of blood-contaminated CSF samples). CSF was collected from 4 patients (on the same day, 8 CSF tubes per patient). For all 4 patients, blood was drawn into serum BD Vacutainer ${ }^{\circ}$ tubes (Becton Dickinson $\mathrm{AB}$, Stockholm, Sweden) and added to 6 CSF tubes from the same individual (final volume $0.01 \%$ [2 CSF tubes], $0.02 \%$ [2 CSF tubes], and 0.04\% [2 CSF tubes]) immediately after CSF collection, whereas the remaining 2 tubes contained neat CSF (Additional file 1: Figure S6). A total of 4 tubes per patient (1 neat CSF, 1 CSF-0.01\%-blood, 1 CSF-0.02\%-blood, and 1 CSF-0.04\%-blood tubes) were centrifuged within $2 \mathrm{~h}$ after collection $(2000 \mathrm{~g}, 10 \mathrm{~min})$. The other 4 tubes ( 1 neat CSF, 1 CSF-0.01\%-blood, 1 CSF-0.02\%-blood, and 1 CSF-0.04\%-blood tubes) were not centrifuged. From all 4 participants, all 8 CSF tubes were analyzed on the day of collection. After analysis, CSF and CSF-blood samples (centrifuged and non-centrifuged) were stored at RT (Additional file 1: Figure S6). In addition to baseline, CSF samples from all 8 tubes were analyzed at $24 \mathrm{~h}, 72 \mathrm{~h}$, and 1 week, after collection. Samples were mixed for 15 min using a roller mixer immediately before the analysis. CSF A 342 were measured using EI kits.

\section{CSF collection gradient}

CSF was collected from 10 patients. For each patient, four 5-ml portions (P1-P4) of CSF were collected into 5-ml LoB tubes (Eppendorf Nordic A/S, Hørsholm, Denmark) after discarding the first $2 \mathrm{ml}$. CSF samples were centrifuged after LP (2000g, $10 \mathrm{~min})$, and $1 \mathrm{ml}$ was aliquoted into 2-ml LoB tubes (Sarstedt AG \& Co., Nümbrecht, Germany) followed by storage at $-80^{\circ} \mathrm{C}$. CSF $\mathrm{A} \beta 42$ and $\mathrm{A} \beta 40$ were measured in $\mathrm{P} 1-\mathrm{P} 4$ portions using $\mathrm{EI}$ and MSD kits.

\section{$A \beta$ measurements}

CSF samples were analyzed using EI $A \beta 42$ and $A \beta 40$ kits and MSD V-plex A $\beta$ peptide panel kit (6E10) and according to the manufacturer's recommendations. All samples within the same pre-analytical protocol were analyzed using the same batch of the kits. The time delay between LP and the start of the baseline sample analysis was 2-4 h. In MSD runs, samples were analyzed in singlicate because MSD V-plex kit has consistently shown low intra-plate coefficient of variance $(\mathrm{A} \beta 42 \mathrm{CV}<$ $4.3 \%, \mathrm{~A} \beta 40 \mathrm{CV}<10 \%)$ in our previous analyses. For EI kit, all samples were analyzed in duplicate. EI and MSD assays were run in parallel. Each plate included 2 quality control (QC) samples (frozen aliquots of low- and highconcentration $A \beta 42$ or $A \beta 40$ provided in the respective EI kits and 2 pooled CSF samples for MSD assays) that were analyzed in duplicate.

\section{Statistical analyses}

SPSS version 22 (IBM, Armonk, NY, USA) and R version 3.4.3 (RStudio) [17] were used for statistical analysis. When two CSF tubes from individual study participants 
were included per experimental condition, the mean biomarker concentrations were used in statistical analysis. Changes in the biomarker levels were analyzed with a mixed-effects model including participant identification as a random effect and treatment groups (temperature, centrifugation, and/or blood contamination), time, and time $\times$ treatment group interactions as fixed factors. Marginal and conditional $R^{2}$ values were computed using the method described by Nakagawa and Schielzeth [18]. To further examine significant interactions, simple main effects analysis and least significant difference post hoc test were performed. The average inter-assay $\mathrm{CVs}$ for QC samples were $4 \%$ for EI A $\beta 42$ (4.4\% and 3.6\% for individual QCs) and $\mathrm{A} \beta 40$ (3.4\% and $4.1 \%$ for individual QCs), $9 \%$ for $\mathrm{A} \beta 42^{\mathrm{MSD}}$ (8.7\% and $9.1 \%$ for individual $\mathrm{QCs}$ ), and $11 \%$ for $\mathrm{A} \beta 40^{\mathrm{MSD}}$ (10.8\% and $11.7 \%$ for individual $\mathrm{QCs}$ ) assays. $\mathrm{A} \beta$ concentrations in the same $\mathrm{QC}$ samples analyzed on different plates varied on average by approximately $5 \%$ and $10 \%$ for EI and MSD assays, respectively. Consequently, for changes in the biomarker levels within these ranges, it was not possible to determine whether they were caused by inter-plate variability or pre-analytical factors. Therefore, only changes exceeding 5\% for EI assays and 10\% for MSD assays were considered to be due to pre-analytical sample handling and tested in statistical analysis.

\section{Results}

In CSF samples from all study participants analyzed on the day of collection, the median (range) values for $\mathrm{A} \beta 42^{\mathrm{EI}}, \mathrm{A} \beta 40^{\mathrm{EI}}, \mathrm{A} \beta 42 / \mathrm{A} \beta 40^{\mathrm{EI}}, \mathrm{A} \beta 42^{\mathrm{MSD}}, \mathrm{A} \beta 40^{\mathrm{MSD}}$, and $\mathrm{A} \beta 42 / \mathrm{A} \beta 40^{\mathrm{MSD}}$ were $747 \mathrm{pg} / \mathrm{ml}(353-1892 \mathrm{pg} / \mathrm{ml}), 8343$ $\mathrm{pg} / \mathrm{ml} \quad(3541-12933 \mathrm{pg} / \mathrm{ml}), 0.13(0.05-0.23), 511 \mathrm{pg} / \mathrm{ml}$ $(198-1554 \mathrm{pg} / \mathrm{ml}), 6249 \mathrm{pg} / \mathrm{ml}(2813-12094 \mathrm{pg} / \mathrm{ml})$, and $0.11(0.04-0.18)$, respectively (Additional file 1: Figure S7).

\section{CSF storage at different temperatures}

We sought to established optimal temperatures for CSF storage after collection and before $A \beta$ analysis. $A \beta 42$ and $A \beta 40$ were measured on the day of CSF collection (baseline) and after storage at either RT or $4{ }^{\circ} \mathrm{C}$ for $24 \mathrm{~h}$, $48 \mathrm{~h}, 72 \mathrm{~h}, 1$ week, and 2 weeks (Fig. 1). In the mixed-effect model for $\mathrm{A} \beta 42^{\mathrm{EI}}$ (marginal and conditional $R^{2}$ values of 0.004 and 0.995 , respectively), there was a significant time $\times$ temperature interaction $(F=4.6, p<0.001)$, and therefore, we performed simple main affects analysis for changes in the biomarker levels that exceeded $5 \%$. In samples kept at $4{ }^{\circ} \mathrm{C}, \mathrm{A} \beta 42^{\mathrm{EI}}$ levels were within $95-105 \%$ range of baseline at all time points (Fig. 1a). However, for samples stored at RT, the $\mathrm{A} \beta 42^{\mathrm{EI}}$ levels decreased by $6 \%$ after 1 week $(p<0.001)$ and $10 \%$ after 2 weeks $(p<0.001)$. $\mathrm{A} \beta 40^{\mathrm{EI}}$ levels were within $95-100 \%$ range of baseline at both temperatures and all time points (Fig. 1b) and were not tested in statistical analysis. For $A \beta 42 /$ $\mathrm{A} \beta 40^{\mathrm{EI}}$, we found a significant effect of time $(F=10.3$, $p<0.001)$ but no significant time $\times$ temperature interaction (marginal and conditional $R^{2}$ values of 0.005 and 0.987 , respectively). A $\beta 42 / \mathrm{A} \beta 40^{\mathrm{EI}}$ decreased by $8 \%$ and $7 \%$ when samples were stored for 2 weeks at RT and $4{ }^{\circ} \mathrm{C}$, respectively $(p<0.001$; Fig. $1 c)$. The results were similar for the MSD assays (Fig. 1d-f). For baseline biomarker measurements, CSF samples from 10 different tubes per patients were analyzed on the day of LP. The mean CV values for these baseline measurements (10 tubes per patient, 12 patients) were $2.0 \%, 2.6 \%, 2.8 \%, 3.0 \%, 4.1$, and $4.3 \%$ for $\mathrm{A} \beta 42^{\mathrm{EI}}$, $\mathrm{A} \beta 40^{\mathrm{EI}}, \mathrm{A} \beta 42 / \mathrm{A} \beta 40^{\mathrm{EI}}, \mathrm{A} \beta 42^{\mathrm{MSD}}, \mathrm{A} \beta 40^{\mathrm{MSD}}$, and $\mathrm{A} \beta 42 /$ $\mathrm{A} \beta 40^{\mathrm{MSD}}$, respectively.

Next, we compared A $\beta$ concentrations in CSF samples that were stored at $-20^{\circ} \mathrm{C}$ or $-80{ }^{\circ} \mathrm{C}$ for 2 weeks after collection. $\mathrm{A} \beta 42^{\mathrm{EI}}, \mathrm{A} \beta 40^{\mathrm{EI}}$, and $\mathrm{A} \beta 42 / \mathrm{A} \beta 40^{\mathrm{EI}}$ were all within $95-105 \%$ range of baseline at both temperatures (Fig. 2a-c). The results were similar for the MSD assays (Fig. 2d-f).

\section{Mixing of CSF before $A \beta$ measurements}

Here, we investigated if it is necessary to mix CSF samples prior to $A \beta$ measurements. $A \beta 42$ and $A \beta 40$ concentrations were determined in mixed and unmixed CSF samples on the day of collection and after storage at either RT or $4{ }^{\circ} \mathrm{C}$ for $24 \mathrm{~h}, 48 \mathrm{~h}, 72 \mathrm{~h}$, and 1 week. $\mathrm{A} \beta 42^{\mathrm{EI}}$, $\mathrm{A} \beta 40^{\mathrm{EI}}$, and $\mathrm{A} \beta 42 / \mathrm{A} \beta 40^{\mathrm{EI}}$ in unmixed CSF samples were within $95-105 \%$ range of the mixed samples at both temperature and all time points (Fig. $3 \mathrm{a}-\mathrm{c}$ ). The results were similar for the MSD assays (Fig. 3d-f).

For frozen CSF samples that were not mixed after thawing, we observed high variability in the mean change from baseline $(A \beta 42 C V=15.5 \%)$ compared to mixed sample $(A \beta 42$ $\mathrm{CV}=2.7 \%)$.

\section{Centrifugation and blood contamination}

We also assessed the effects of centrifugation after LP and/or blood contamination on $A \beta$ levels in CSF stored at different temperatures for $24 \mathrm{~h}, 72 \mathrm{~h}, 1$ week, and 2 weeks after collection.

First, we investigated the effect of centrifugation on A $\beta$ levels in neat (without added blood) CSF. We did not observe differences in the biomarker levels between neat centrifuged and non-centrifuged CSF samples stored for up to 2 weeks at $\mathrm{RT}, 4{ }^{\circ} \mathrm{C}$, or $-20^{\circ} \mathrm{C}$ (Additional file 1: Figure S8).

Next, we studied the effects of adding fresh blood to fresh CSF. In the initial experiments, we examined the effects of $0.1 \%$ and $10 \%$ blood on CSF $\mathrm{A} \beta 42^{\mathrm{EI}}$ values over 2 weeks and observed dramatic effects of $10 \%$ blood contamination on $\mathrm{A} \beta 42^{\mathrm{EI}}$ levels, which was partly mitigated by centrifugation and/or storage at $4{ }^{\circ} \mathrm{C}$ (Fig. 4a). 

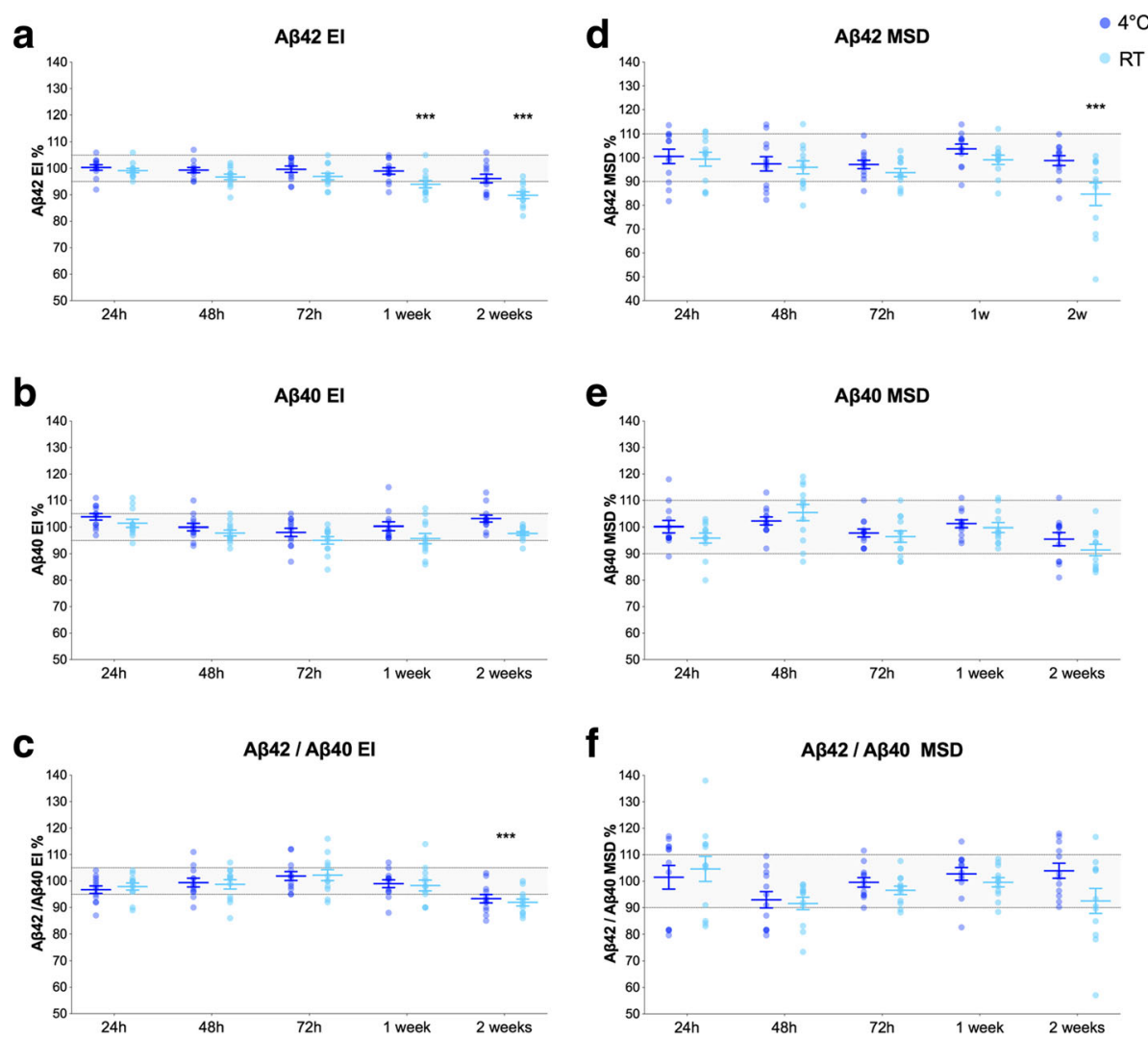

Fig. $1 \mathrm{CSF}$ storage at $\mathrm{RT}$ and $4^{\circ} \mathrm{C}$. $A \beta 42^{\mathrm{El}}(\mathbf{a}), A \beta 40^{\mathrm{El}}(\mathbf{b}), A \beta 42 / A \beta 40^{\mathrm{El}}(\mathbf{c}), A \beta 42^{\mathrm{MSD}}(\mathbf{d}), A \beta 40^{\mathrm{MSD}}$ (e), and $A \beta 42 / A \beta 40^{\mathrm{MSD}}$ (f) in CSF samples that were stored at either RT or $4^{\circ} \mathrm{C}$ for up to 2 weeks after collection (12 patients, 10 CSF tubes per patient). Data are shown as the percentage of biomarker levels in fresh, non-processed, CSF samples (from the same donor) that were analyzed within hours after LP. The effects of preanalytical factors were tested using the mixed-effects model including participant identification as a random effect and temperature, time, and time $\times$ temperature interactions as fixed factors. The gray areas represent $95-105 \%$ and $90-110 \%$ ranges for the El and MSD assays, respectively, that were set based on the inter-assay CVs as described in the "Materials and methods" section. Only changes in the mean biomarker levels outside these ranges (gray areas) were considered to be due to pre-analytical sample handling and examined using post hoc tests. ${ }^{*} p \leq 0.05$, ${ }^{* *} p \leq 0.01,{ }^{* * *} p \leq 0.001$. Horizontal lines and error bars represent mean \pm SEM. Abbreviations: A $\beta, \beta$-amyloid; El, EUROIMMUN; $h$, hours; MSD, mesoscale discovery; RT, room temperature; SEM, standard error of mean

Because we found an effect of blood contamination on CSF A $\beta 42$, we made more detailed analyses assessing how $0.1 \%, 1.0 \%$, and $10 \%$ blood contamination affects the CSF levels of $\mathrm{A} \beta 42^{\mathrm{MSD}}, \mathrm{A} \beta 40^{\mathrm{MSD}}$, and $\mathrm{A} \beta 42 /$ $\mathrm{A} \beta 40^{\mathrm{MSD}}$ over 2 weeks of storage. In the mixed-effect model for $\mathrm{A} \beta 42$ (marginal and conditional $R^{2}$ values of 0.309 and 0.890 , respectively) and $A \beta 40$ (marginal and conditional $R^{2}$ values of 0.311 and 0.877 , respectively), there were significant time $\times$ treatment group interactions $(F=2.2-27.0, p<0.001)$, and therefore, we performed simple main affects analysis for changes in the biomarker levels exceeding 5\%. Again, we found that blood contamination led to a dose- and time-dependent decrease (by 14-98\%) in $A \beta 42$ and $A \beta 40$ (Fig. 5a, b). Interestingly, $A \beta 42 / A \beta 40$ ratio did not change in CSF samples that were stored at RT without centrifugation (Fig. 5c). The effects of blood contamination on CSF $A \beta 42$ and $A \beta 40$ levels were partially mitigated by centrifugation or storage at $4{ }^{\circ} \mathrm{C}$, and when combining centrifugation with storage at $4{ }^{\circ} \mathrm{C}$, there were no effects even when adding $10 \%$ blood. Further, centrifugation and storage at $-20^{\circ} \mathrm{C}$ effectively blocked the effects of up to $10 \%$ blood contamination on CSF A $\beta 42$ and A $\beta 40$ levels (Fig. 5d-f).

The largest reduction in CSF levels of $A \beta$ was seen for non-centrifuged samples stored at room temperature. Therefore, we further investigated the effects of blood contamination at levels below $0.1 \%$ on CSF A $\beta 42$ under these conditions. Although blood contamination at $0.04 \%(2000 \mathrm{E} / \mu \mathrm{l})$ was still visible by the unaided eye, CSF-0.02\%-blood (1000 E/ $\mu$ l) and CSF-0.01\%-blood (500 $\mathrm{E} / \mu \mathrm{l})$ samples were visually indistinguishable from neat CSF (Additional file 1: Figure S4). In non-centrifuged CSF-0.01\%-blood and CSF-0.02\%-blood samples, A $\beta 42$ levels were stable for up to 1 week after collection (Fig. 4b). However, the addition of $0.04 \%$ blood caused a 


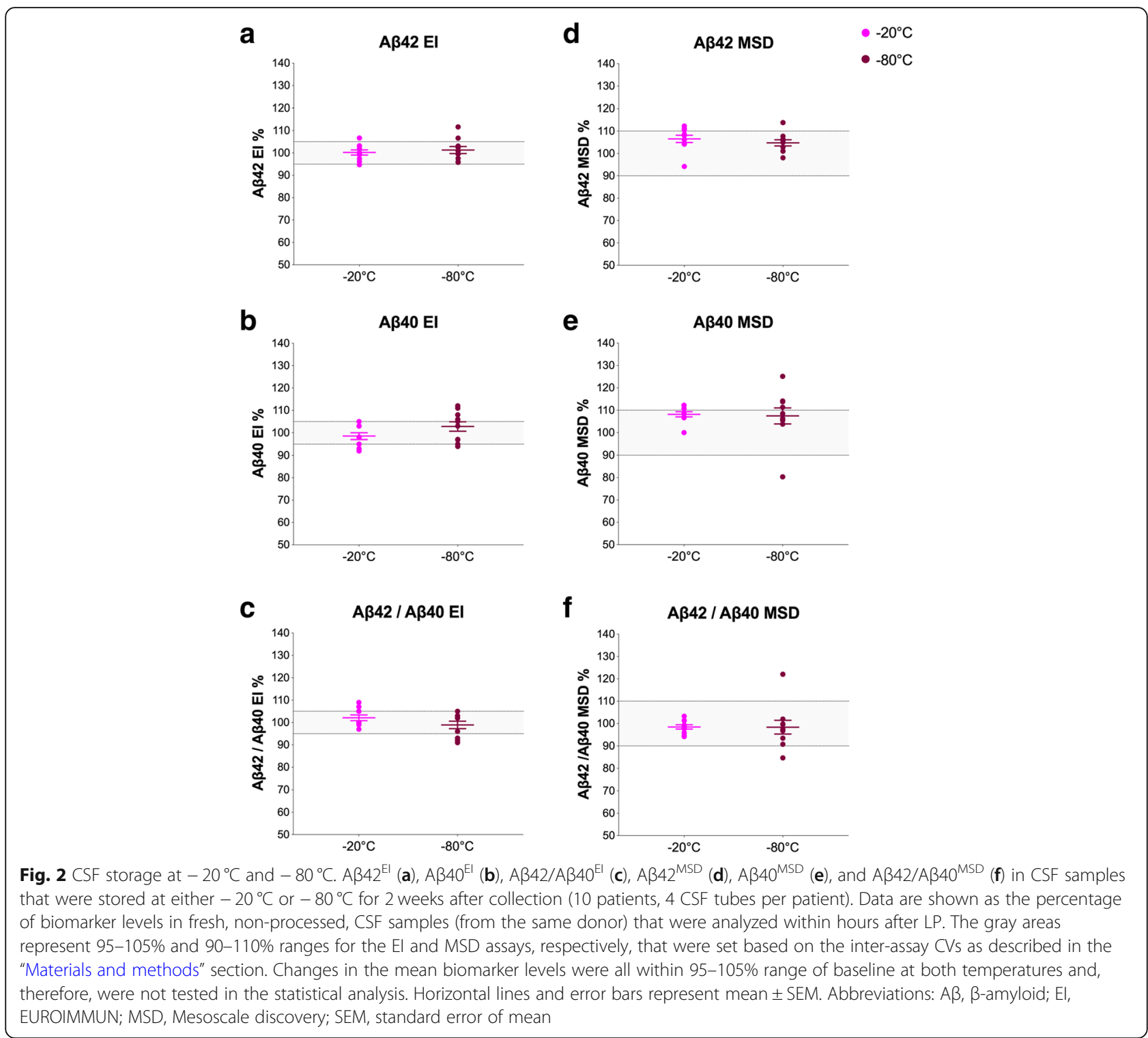

small (5-8\%) decrease in A 342 at $72 \mathrm{~h}$ and 1 week after collection which was again blocked by centrifugation (Fig. 4b).

\section{Collection gradient}

To determine whether the caudal-rostral concentration gradient has an effect on CSF $A \beta$, we measured $A \beta 42$ and $A \beta 40$ in the first to fourth $5-\mathrm{ml}$ fractions of $20 \mathrm{ml}$ CSF collected during LP. When compared with the first fraction, $\mathrm{A} \beta 42^{\mathrm{EI}}, \mathrm{A} \beta 40^{\mathrm{EI}}$, and $\mathrm{A} \beta 42 / \mathrm{A} \beta 40^{\mathrm{EI}}$ were not altered by more than $5 \%$ in any of the other fractions (Fig. 6a-c). The results were similar for the MSD assays (Fig. 6d-f).

\section{Discussion}

The aim of the present study was to perform experiments needed to facilitate the development of a unified standard operating procedure for pre-analytical handling of CSF optimized for A $\beta$ measurements. To this end, we investigated the effects of a number of pre-analytical factors on CSF levels of $A \beta 42$ and $A \beta 40$ using fresh (nonprocessed) CSF samples analyzed within hours after LP as the standard of truth. Our findings indicate that CSF could be stored for at least $72 \mathrm{~h}$ at RT, 1 week at $4{ }^{\circ} \mathrm{C}$, and 2 weeks at $-20^{\circ} \mathrm{C}$ and $-80^{\circ} \mathrm{C}$ without significant changes in the levels of $\mathrm{A} \beta 42$ or $\mathrm{A} \beta 40$. Centrifugation was not needed if the CSF samples were not contaminated with blood. Further, we found that there is no need to mix the CSF samples prior to $A \beta$ measurements, if the samples had not been frozen. In CSF samples that were not centrifuged after LP and stored at RT, blood contamination led to dose- and time-dependent reductions in $A \beta 42$ and $A \beta 40$ levels whereas $A \beta 42 / A \beta 40$ was 

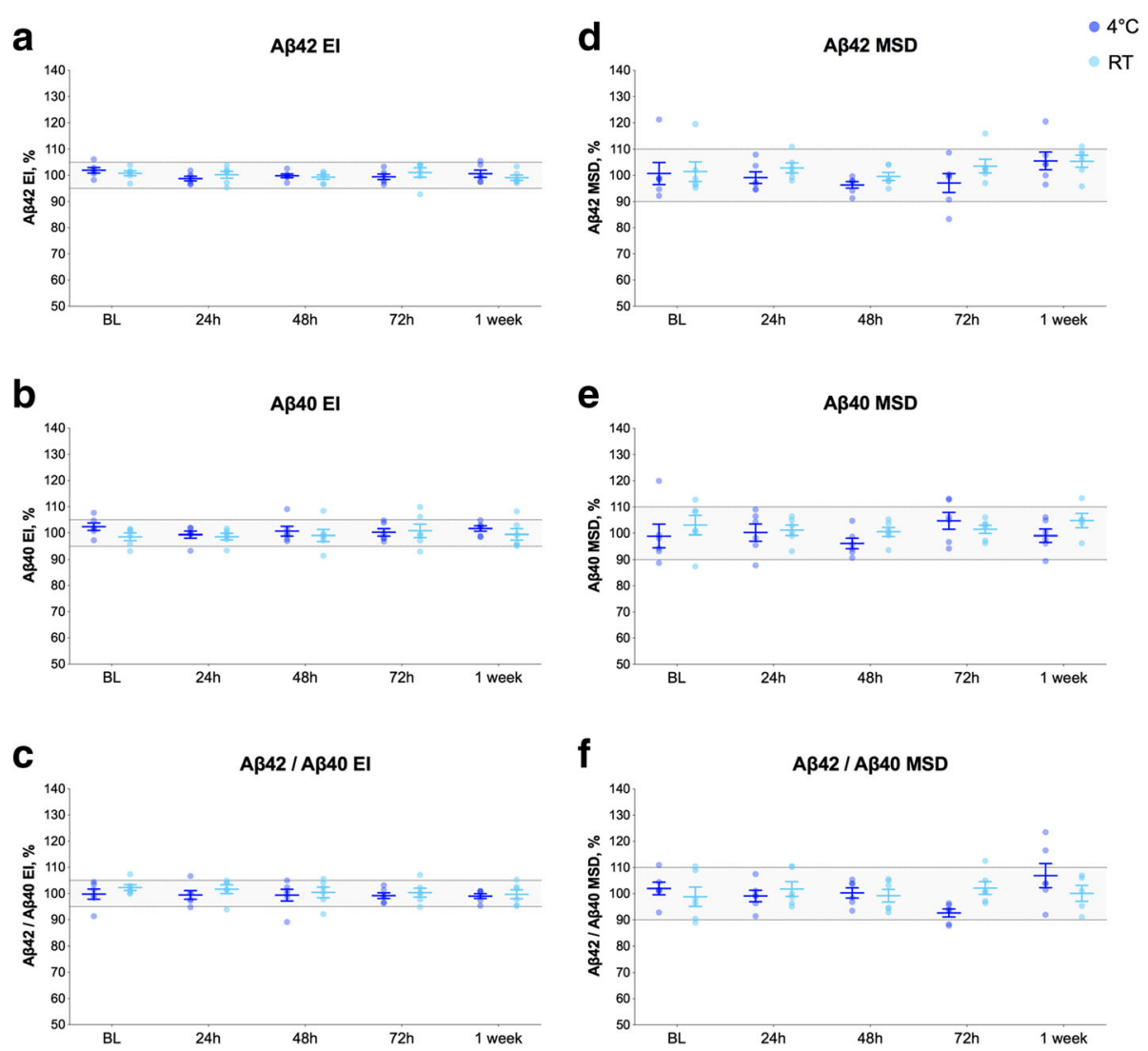

Fig. 3 Mixing of CSF before $A \beta$ measurements. $A \beta 42^{E \mathrm{I}}(\mathbf{a}), A \beta 40^{\mathrm{El}}(\mathbf{b}), A \beta 42 / A \beta 40^{\mathrm{El}}(\mathbf{c}), A \beta 42^{\mathrm{MSD}}(\mathbf{d}), A \beta 40^{\mathrm{MSD}}$ (e), and $A \beta 42 / A \beta 40^{\mathrm{MSD}}(\mathbf{f})$ in $C S F$ samples that were not mixed before $A \beta$ measurements after being stored at either RT or $4^{\circ} \mathrm{C}$ for up to 1 week after collection ( 6 patients, 4 CSF tubes per patient). Data are shown as the percentage of biomarker levels in CSF samples (from the same donor) that were mixed for 15 min using a roller mixer immediately before the analysis and treated the same way with respect to other experimental conditions (temperature and time). The gray areas represent 95-105\% and $90-110 \%$ ranges for the El and MSD assays, respectively, that were set based on the inter-assay CVs as described in the "Materials and methods" section. All biomarker levels in unmixed CSF samples were within 95-105\% range of the mixed samples at both temperature and all time points and, therefore, were not tested in the statistical analysis. Horizontal lines and error bars represent mean \pm SEM. Abbreviations: A $\beta, \beta$-amyloid; $B L$, baseline; El, EUROIMMUN; h, hours; MSD, Mesoscale discovery; RT, room temperature; SEM, standard error of mean

stable. The effects of blood contamination on $A \beta 42$ and A $\beta 40$ were partially to fully mitigated by centrifugation and/or storage at lower temperatures $\left(4^{\circ} \mathrm{C}\right.$ and $\left.-20^{\circ} \mathrm{C}\right)$. Finally, we did not observe differences in $A \beta 42$ and A 340 levels between the first and second to fourth $5-\mathrm{ml}$ portions of $20 \mathrm{ml} \mathrm{CSF}$ collected during LP. Although we used LoB tubes from Sarstedt in the present study, our unpublished data indicates no difference in $A \beta$ levels between CSF samples stored in either Sartstedt or Eppendorf LoB tubes. In principle, LoB tubes available from other vendors could also be suitable for CSF storage before $A \beta$ analysis. Still, their performance should be assessed in comparison to Sartstedt or Eppendorf LoB tubes before incorporation in pre-analytical protocols.

For practical reasons, it is more suitable to transport CSF to clinical chemistry laboratories for testing at RT or at $4{ }^{\circ} \mathrm{C}$. However, at these temperatures, $\mathrm{A} \beta 42$ release from amyloid-binding proteins, adsorption to tube material, or proteolytic degradation may all potentially cause changes in the levels of this peptide [8], particularly in CSF samples stored for several days or longer. Published evidence indicates that $A \beta 42$ is stable when CSF is stored at RT for up to $24 \mathrm{~h}[12,19,20]$. At the same time, data on longer storage have been inconclusive. Some reports have shown that storage for 2-14 days does not affect CSF levels of A $\beta 42$ levels [20-22], while others found both an increase [12] and decrease [23] in $A \beta 42$ concentrations by $15-20 \%$. Using LoB tubes and fresh (non-processed) CSF analyzed within hours after LP as the standard of truth, we observed that $A \beta 42$ and $A \beta 40$ levels were stable for up to 2 weeks and $\mathrm{A} \beta 42 / \mathrm{A} \beta 40$ for up to 1 week when samples were stored at $4{ }^{\circ} \mathrm{C}$. Storage at RT led to $6-10 \%$ decline in $A \beta 42$ and $\mathrm{A} \beta 42 / \mathrm{A} \beta 40$ at 1 and 2 weeks after collection. Collectively, these results indicate that CSF samples could be stored for at least $72 \mathrm{~h}$ at RT and 1 week at $4{ }^{\circ} \mathrm{C}$ without significant changes in $A \beta$. Thus, in these conditions, release from amyloid-binding proteins and proteolytic 


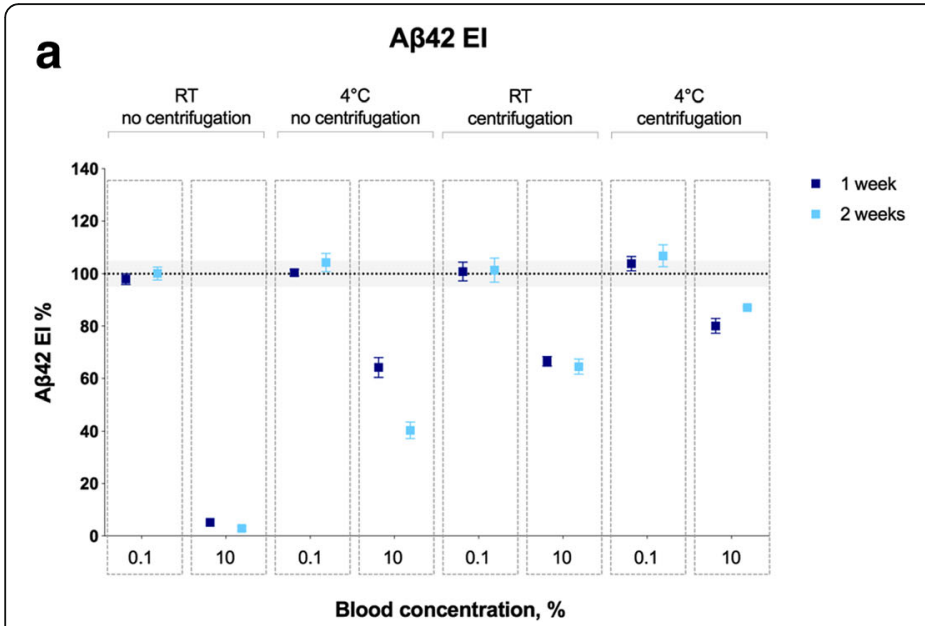

b

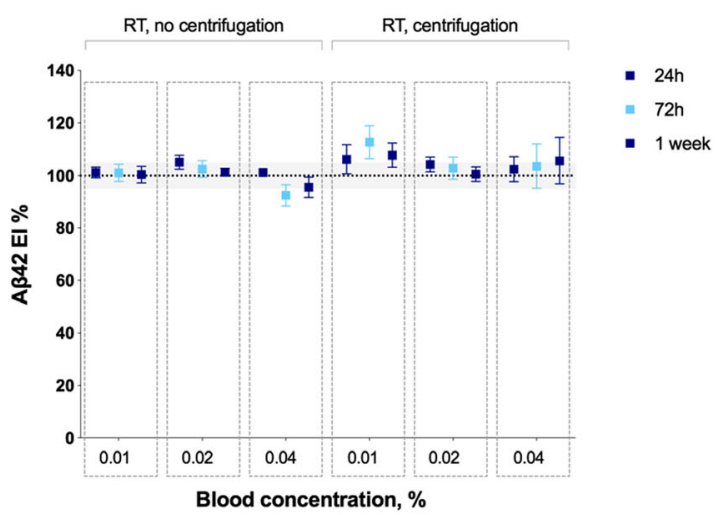

Fig. 4 Blood contamination-El assay. a $A \beta 42^{E l}$ in CSF samples with added $0.1 \%$ or $10 \%$ blood stored at either RT or $4{ }^{\circ} \mathrm{C}$ for up to 2 weeks after collection (4 patients, 12 CSF tubes per patient; except the $10 \%$ blood, $4^{\circ} \mathrm{C}$, centrifugation group from where one sample was excluded due to the technical error during the $A \beta 42$ measurements). b A $A 42^{\mathrm{El}}$ in CSF samples with added $0.01 \%, 0.02$, or $0.04 \%$ blood stored at RT for up to 1 week after collection (4 patients, 8 CSF tubes per patient). Data are shown as the percentage of biomarker levels in neat CSF samples (from the same donor) that were treated the same way with respect to other experimental conditions (centrifugation, temperature, and time). The gray areas represent 95-105\% range that was set based on the inter-assay CVs as described in the "Materials and methods" section. Given the small number of participants, statistical tests were not performed. Horizontal lines and error bars represent mean \pm SEM. Abbreviations: A $\beta$, $\beta$-amyloid; EI, EUROIMMUN; RT, room temperature; SEM, standard error of mean

degradation may have limited effects on CSF levels of A 342 . Of note, the observed changes in the biomarker levels after $72 \mathrm{~h}$ and 1 week were small. Nevertheless, storage of CSF samples longer than these time periods might not be recommended considering that (i) experimental conditions (e.g., temperature) in the present study were tightly controlled which would be difficult to implement in routine clinical practice worldwide and (ii) for biomarker levels that are close to the cutoffs for $A \beta$ abnormality even small changes due to pre-analytical handling could have significant impact on diagnostic process. Corroborating previous data [12], we further demonstrate no differences in $\mathrm{A} \beta 42$ and $\mathrm{A} \beta 40$ between samples stored at $-20^{\circ} \mathrm{C}$ and $-80^{\circ} \mathrm{C}$ for 2 weeks and, therefore, either of the temperatures could be used if freezing of samples before analyses is preferred.

Freezing and thawing procedures introduce concentration gradient in biological samples, and consequently, thorough mixing is needed to make samples homogeneous [24] Accordingly, we found that analysis of unmixed freeze-thawed CSF samples produced unreliable $\mathrm{A} \beta$ values with high variability. However, it is not established whether fresh CSF samples should be mixed prior to $A \beta$ measurements, especially after relatively longer storage at $\mathrm{RT}$ or $4{ }^{\circ} \mathrm{C}$. In the present study, we observed no differences in $A \beta 42$ and $A \beta 40$ between mixed and unmixed fresh CSF samples that were stored at either RT or $4{ }^{\circ} \mathrm{C}$ for up to 1 week after collection. Similarly, one earlier study has shown that vortexing of CSF did not have any significant effects on A $\beta 42$ level [25]. Thus, for CSF samples stored at RT or $4{ }^{\circ} \mathrm{C}$, mixing prior to $\mathrm{A} \beta$ measurements is not required.

Centrifugation of CSF after LP is usually advised to remove white blood cells and, in case of blood contamination, red blood cells that may alter the proteome profile [26-28]. Yet, there is a lack of evidence about the effects of centrifugation on A $\beta 42$ levels in CSF stored at RT or $4{ }^{\circ} \mathrm{C}$ for longer than $24 \mathrm{~h}$, while data for frozen CSF samples are not consistent. Previous studies have shown both no change and a reduction in CSF A 342 after centrifugation [12, 19, 23, 29-31]. However, all of these studies used polypropylene tubes for CSF collection, and only one examined the effects of centrifugation in fresh CSF samples. Thus, a drop in A $\beta 42$ levels due to adsorption to the tube walls and freeze-thaw cycles might have confounded the reported results. Here, using the LoB tube and fresh CSF analyzed within hours after LP as the standard of truth, we demonstrate that centrifugation after LP does not affect $A \beta 42$ and $A \beta 40$ levels in non-hemorrhagic CSF samples stored at RT, $4{ }^{\circ} \mathrm{C}$, and $20^{\circ} \mathrm{C}$ for up to 2 weeks after collection. Hence, for CSF samples with no visible blood contamination, centrifugation is not necessary.

In agreement with previous data [19], we observed that blood contamination alters CSF levels of $A \beta$. Addition of $0.04-10 \%$ of blood corresponding to $2 \times$ $10^{3}-5 \times 10^{5} \mathrm{E} / \mu \mathrm{l}$ to CSF samples caused a 5-98\% decline in $A \beta 42$ and $A \beta 40$ concentrations which was more pronounced and occurred earlier with increasing degree of blood contamination. At this level, blood contamination 


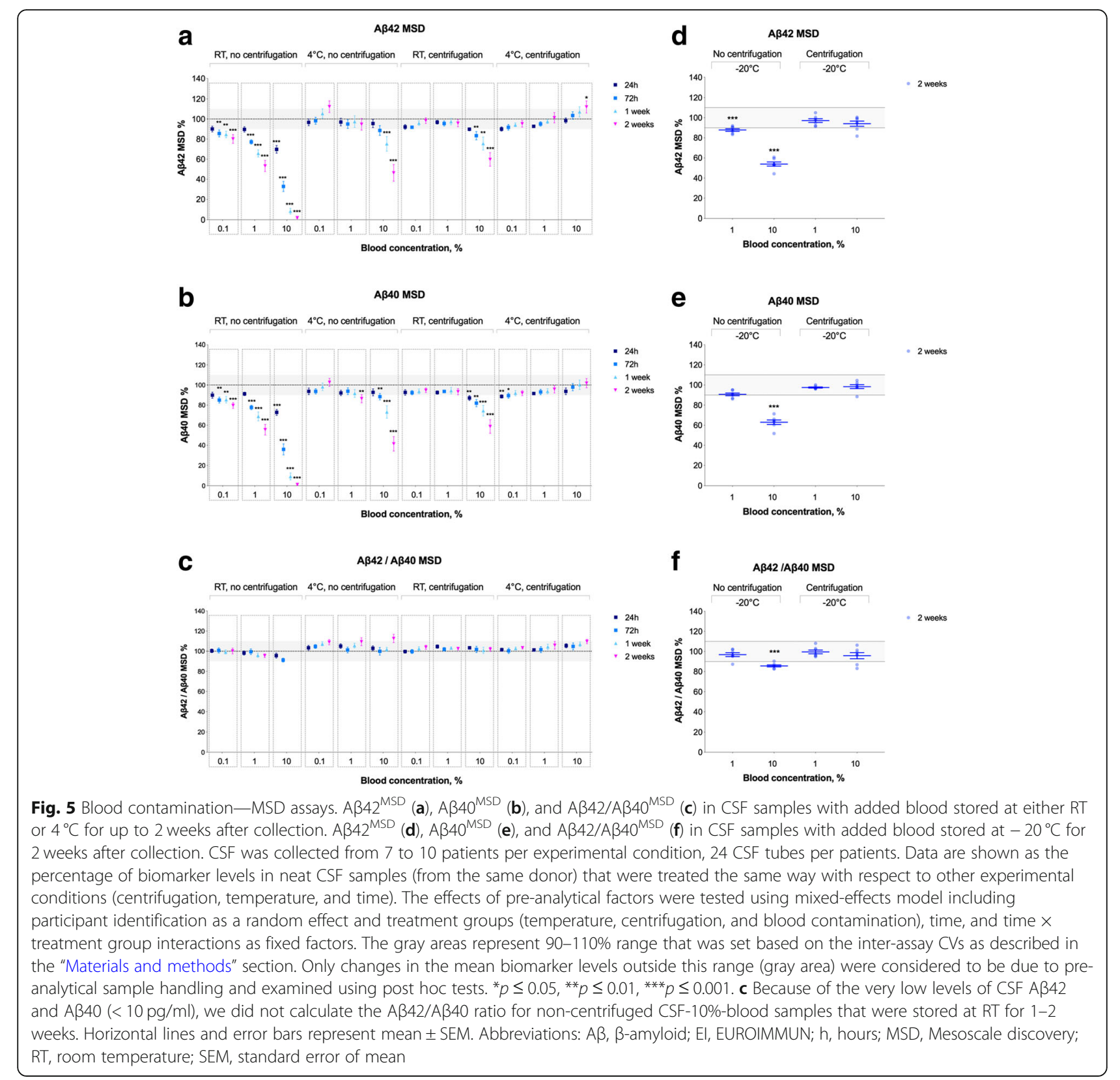

was visible by the unaided eye (Additional file 1: Figure S4). Notably, centrifugation and/or storage at lower temperatures $\left(4^{\circ} \mathrm{C}\right.$ and $\left.-20^{\circ} \mathrm{C}\right)$ mitigated the effects of blood contamination. A possible explanation for these findings could be that centrifugation and low temperatures attenuate the binding and degradation of CSF A $\beta$ peptides by blood-derived proteins that have been suggested to affect the biomarker levels in blood-contaminated samples [8]. The magnitude of decrease in CSF $A \beta 42$ and $A \beta 40$ concentrations was similar, and consequently, $\mathrm{A} \beta 42 / \mathrm{A} \beta 40$ was not significantly influenced by blood contamination. In line with our data, previous investigations have demonstrated that $A \beta 42 / A \beta 40$ showed improved accuracy for $A D$ diagnosis [2] and superior concordance with amyloid PET [32-35] in part by normalizing variability due to pre-analytical factors [11, 25, 36, 37]. We did not observe any effects of blood contamination at levels that were not visible by the

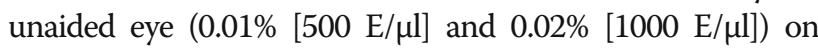
CSF A 342 . Taken together, our findings suggest that for CSF samples with more than $1000 \mathrm{E} / \mu \mathrm{l}$ blood contamination or visible blood contamination (if erythrocyte count is not available), centrifugation and storage at $4{ }^{\circ} \mathrm{C}$ or $-20^{\circ} \mathrm{C}$ should be recommended.

Some proteins show differences in concentrations between lumbar and ventricular CSF, suggesting the existence of rostro-caudal concentration gradient [38-40]. 


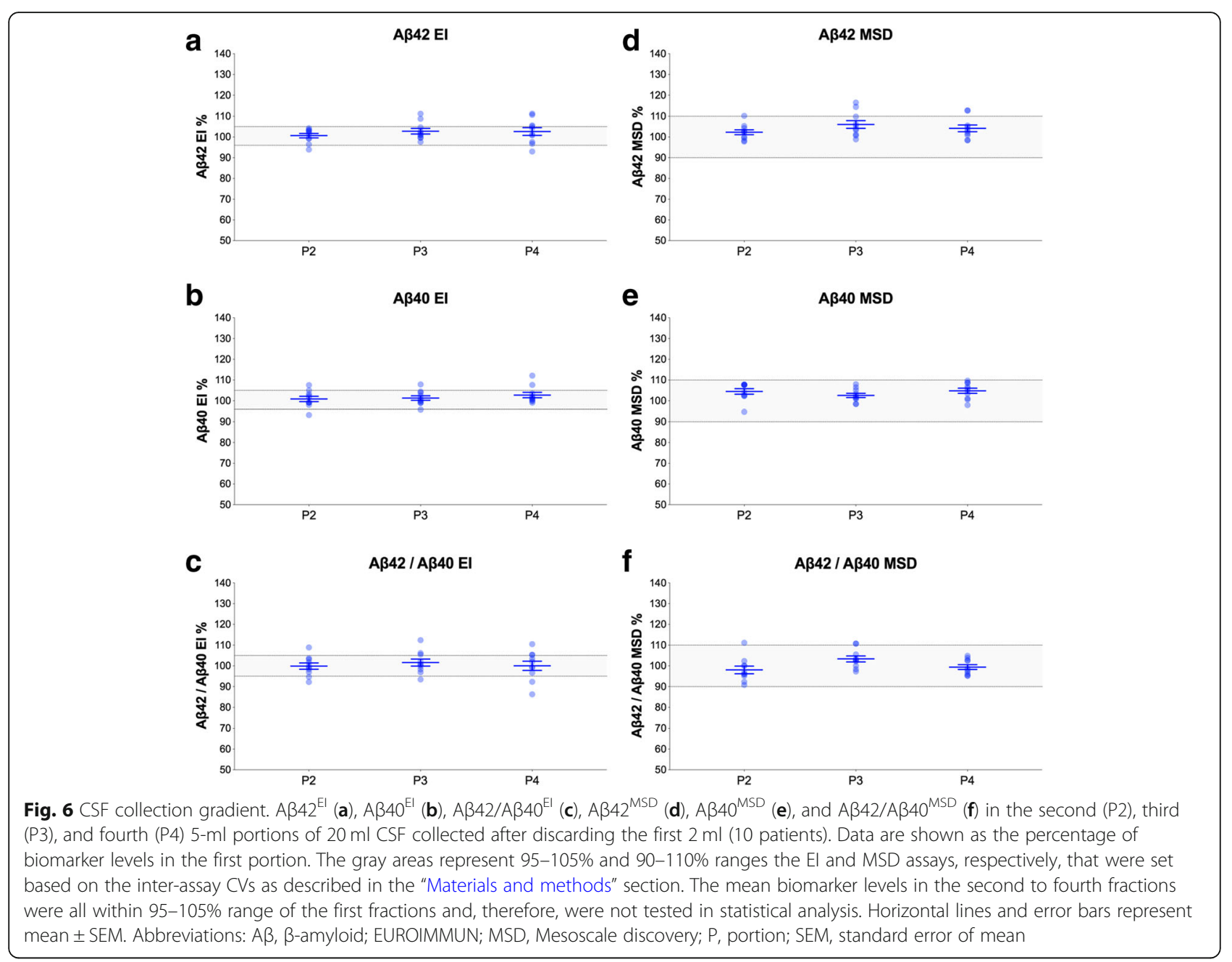

Such a gradient would imply that biomarker levels vary depending on the volume and fraction of CSF collected during LP. Speaking against rostro-caudal concentration gradient for $\mathrm{A} \beta$ and in agreement with previous studies, we did not observe any differences in $A \beta 42$ and $A \beta 40$ levels between the first to fourth 5-ml portions of CSF.

One limitation of the present study is bias associated with inter-assay variability. For example, in the case of the EI assays, we observed $5 \%$ fluctuations in the biomarker concentrations due to run-to-run variance in assay performance. Consequently, we were unable to reliably detect changes caused by pre-analytical factors that were below $5 \%$.

\section{Conclusions}

The conclusions of the present study are as follows: (1) any portion of up to $20 \mathrm{ml}$ of CSF (after discarding the first $2 \mathrm{ml}$ ) could be used for $A \beta$ analysis, (2) CSF should be collected directly into a LoB tube, (3) centrifugation of CSF after LP is not necessary if erythrocyte count is $\leq 1000 / \mu \mathrm{l}$ or no visible blood contamination, (4) fresh CSF samples could be stored at RT for $72 \mathrm{~h}$ or at $4{ }^{\circ} \mathrm{C}$ for 1 week until analyses, (5) mixing of fresh CSF samples before $A \beta$ measurement is not required, and (6) CSF samples with visible blood contamination should be centrifuged after LP and stored at $4{ }^{\circ} \mathrm{C}$. An alternative approach is to store the CSF collected directly into a LoB tube at $-20^{\circ} \mathrm{C}$ or $-80^{\circ} \mathrm{C}$ until analyses. The frozen samples should be handled similar to the fresh samples (see above), except that mixing of the thawed samples should be done just before analyses. Although the findings of the present study were very similar for EI and MSD assays, they should be verified for other available A $\beta$ assays/platforms. A final unified pre-analytical protocol must be decided in consensus by the main stakeholders in the field. This effort is currently led by the Alzheimer's Association.

\section{Additional file}

Additional file 1: Figure S1. Flowchart of the CSF storage protocol. Figure S2. Flowchart of the CSF mixing protocol. Figure S3. Flowchart of the blood contamination $(0.1 \%, 1 \%, 10 \%)$ and centrifugation 
protocol_El assay. Figure S4. CSF-blood samples. Figure S5. Samples and analysis in blood contamination and centrifugation protocol—MDS assay. Figure S6. Flowchart of blood contamination at low levels $(0.01 \%$, $0.02 \%, 0.04 \%$ ) and the centrifugation protocol-El assay. Figure S7. Frequency plots of CSF biomarkers. Figure S8. Effects of centrifugation when not adding blood. (DOCX $8700 \mathrm{~kb}$ )

\section{Abbreviations}

AD: Alzheimer's disease; $A \beta$ : $\beta$-Amyloid; CSF: Cerebrospinal fluid; CV: Coefficient of variance; El: EUROIMMUN; LoB: Low binding; LP: Lumbar puncture; MSD: Mesoscale discovery; P: Portion; RT: Room temperature

\section{Acknowledgements}

The authors thank the study participants and the research nurses involved in the study. Without their invaluable contribution, this study would not have been possible.

\section{Authors' contributions}

$\mathrm{SJ}, \mathrm{ES}, \mathrm{BB}$, and $\mathrm{OH}$ collected the data and reviewed the manuscript for intellectual content. SJ and $\mathrm{OH}$ analyzed and interpreted the data, prepared the figures, and co-wrote the manuscript. $\mathrm{OH}$ was the principal designer and coordinator of the study and overviewed the collection, analysis, and interpretation of the study data.

\section{Funding}

The study was supported by the European Research Council, the Swedish Research Council, the Knut and Alice Wallenberg Foundation, the Marianne and Marcus Wallenberg Foundation, the Strategic Research Area MultiPark (Multidisciplinary Research in Parkinson's disease) at Lund University, the Swedish Alzheimer Foundation, the Swedish Brain Foundation, The Parkinson Foundation of Sweden, The Parkinson Research Foundation, the Skåne University Hospital Foundation, and the Swedish federal government under the ALF agreement. The funding sources had no role in the design and conduct of the study; in the collection, analysis, and interpretation of the data; or in the preparation, review, or approval of the manuscript. $A \beta 42^{E \mathrm{E}}$ and $A \beta 40^{\mathrm{EI}}$ kits were generously provided by EUROIMMUN.

\section{Availability of data and materials}

Anonymized data will be shared by request from any qualified investigator for the sole purpose of replicating procedures and results presented in the article and as long as data transfer is in agreement with EU legislation on the general data protection regulation.

\section{Ethics approval and consent to participate}

De-identified CSF samples from 53 patients were used in this study. All patients gave their written informed consent allowing their CSF samples to be used for research.

\section{Consent for publication}

Not applicable.

\section{Competing interests}

Drs Janelidze and Stomrud declare that they have no competing interests. Dr. Brix is employed by Euroimmun. Dr. Hansson has acquired research support (for the institution) from Roche, GE Healthcare, Biogen, AVID Radiopharmaceuticals, Fujirebio, and Euroimmun. In the past 2 years, he has received consultancy/speaker fees (paid to the institution) from Biogen, Roche, and Fujirebio.

\section{Author details}

'Department of Clinical Sciences Malmö, Clinical Memory Research Unit, Lund University, Sölvegatan 19, BMC B11, 22184 Lund, Sweden. ${ }^{2}$ Memory Clinic, Skåne University Hospital, Simrisbanvägen 14, SE-20502 Malmö, Sweden. ${ }^{3}$ EUROIMMUN AG, 23560 Luebeck, Germany.
Received: 12 February 2019 Accepted: 8 July 2019

Published online: 19 July 2019

\section{References}

1. Albert MS, Dekosky ST, Dickson D, Dubois B, Feldman HH, Fox NC, et al. The diagnosis of mild cognitive impairment due to Alzheimer's disease: recommendations from the National Institute on Aging-Alzheimer's Association workgroups on diagnostic guidelines for Alzheimer's disease. Alzheimers Dement. 2011;7(3):270-9.

2. Dubois B, Feldman HH, Jacova C, Hampel H, Molinuevo JL, Blennow K, et al. Advancing research diagnostic criteria for Alzheimer's disease: the IWG-2 criteria. Lancet Neurol. 2014;13(6):614-29.

3. Shaw LM, Arias J, Blennow K, Galasko D, Molinuevo JL, Salloway S, et al. Appropriate use criteria for lumbar puncture and cerebrospinal fluid testing in the diagnosis of Alzheimer's disease. Alzheimers Dement. 2018;14(11):1505-21.

4. Bittner T, Zetterberg H, Teunissen CE, Ostlund RE Jr, Militello M, Andreasson U, et al. Technical performance of a novel, fully automated electrochemiluminescence immunoassay for the quantitation of beta-amyloid (1-42) in human cerebrospinal fluid. Alzheimers Dement. 2016;12(5):517-26.

5. Chiasserini D, Biscetti L, Farotti L, Eusebi P, Salvadori N, Lisetti V, et al. Performance evaluation of an automated ELISA system for Alzheimer's disease detection in clinical routine. J Alzheimers Dis. 2016;54(1):55-67.

6. Kuhlmann J, Andreasson U, Pannee J, Bjerke M, Portelius E, Leinenbach A, et al. CSF Abeta1-42 - an excellent but complicated Alzheimer's biomarker - a route to standardisation. Clin Chim Acta. 2017;467:27-33.

7. Leinenbach A, Pannee J, Dulffer T, Huber A, Bittner T, Andreasson U, et al. Mass spectrometry-based candidate reference measurement procedure for quantification of amyloid-beta in cerebrospinal fluid. Clin Chem. 2014;60(7):987-94.

8. Hansson O, Mikulskis A, Fagan AM, Teunissen C, Zetterberg H, Vanderstichele $\mathrm{H}$, et al. The impact of preanalytical variables on measuring cerebrospinal fluid biomarkers for Alzheimer's disease diagnosis: a review. Alzheimers Dement. 2018;14(10):1313-33.

9. Hansson O, Seibyl J, Stomrud E, Zetterberg H, Trojanowski JQ, Bittner T, et al. CSF biomarkers of Alzheimer's disease concord with amyloid-beta PET and predict clinical progression: a study of fully automated immunoassays in BioFINDER and ADNI cohorts. Alzheimers Dement. 2018;14(11):1470-81.

10. Toombs J, Foiani MS, Wellington H, Paterson RW, Arber C, Heslegrave A, et al. Amyloid beta peptides are differentially vulnerable to preanalytical surface exposure, an effect incompletely mitigated by the use of ratios. Alzheimers Dement (Amst). 2018;10:311-21.

11. Vanderstichele HM, Janelidze S, Demeyer L, Coart E, Stoops E, Herbst V, et al. Optimized standard operating procedures for the analysis of cerebrospinal fluid Abeta42 and the ratios of Abeta isoforms using low protein binding tubes. J Alzheimers Dis. 2016;53(3):1121-32.

12. Le Bastard N, De Deyn PP, Engelborghs S. Importance and impact of preanalytical variables on Alzheimer disease biomarker concentrations in cerebrospinal fluid. Clin Chem. 2015;61(5):734-43.

13. Toombs J, Paterson RW, Lunn MP, Nicholas JM, Fox NC, Chapman MD, et al. Identification of an important potential confound in CSF AD studies: aliquot volume. Clin Chem Lab Med. 2013;51(12):2311-7.

14. Toombs J, Paterson RW, Nicholas JM, Petzold A, Schott JM, Zetterberg H. The impact of Tween 20 on repeatability of amyloid beta and tau measurements in cerebrospinal fluid. Clin Chem Lab Med. 2015;53(12):e329-32.

15. Vanderstichele H, Demeyer L, Janelidze S, Coart E, Stoops E, Mauroo K, et al. Recommendations for cerebrospinal fluid collection for the analysis by ELISA of neurogranin trunc P75, alpha-synuclein, and total tau in combination with Abeta (1-42)/Abeta (1-40). Alzheimers Res Ther. 2017;9(1):40.

16. Cullen VC, Fredenburg RA, Evans C, Conliffe PR, Solomon ME. Development and advanced validation of an optimized method for the quantitation of Abeta42 in human cerebrospinal fluid. AAPS J. 2012;14(3):510-8.

17. Team RC. R: a language and environment for statistical computing. R Foundation for Statistical Computing, Vienna, Austria. 2014;URL http://www.R-project.org/.

18. Nakagawa S, Schielzeth $H$. A general and simple method for obtaining R2 from generalized linear mixed-effects models. Methods Ecol Evol. 2013;4(2):133-42.

19. Bjerke $M$, Portelius $E$, Minthon L, Wallin $A$, Anckarsater $H$, Anckarsater $R$, et al. Confounding factors influencing amyloid Beta concentration in cerebrospinal fluid. Int J Alzheimers Dis. 2010;2010:1-11.

20. Paterson RW, Toombs J, Chapman MD, Nicholas JM, Heslegrave AJ, Slattery CF, et al. Do cerebrospinal fluid transfer methods affect measured amyloid beta42, total tau, and phosphorylated tau in clinical practice? Alzheimers Dement (Amst). 2015;1(3):380-4. 
21. Simonsen AH, Bahl JM, Danborg PB, Lindstrom V, Larsen SO, Grubb A, et al. Pre-analytical factors influencing the stability of cerebrospinal fluid proteins. J Neurosci Methods. 2013;215(2):234-40.

22. Zimmermann R, Lelental N, Ganslandt O, Maler JM, Kornhuber J, Lewczuk P. Preanalytical sample handling and sample stability testing for the neurochemical dementia diagnostics. J Alzheimers Dis. 2011;25(4):739-45.

23. Schoonenboom NS, Mulder C, Vanderstichele H, Van Elk EJ, Kok A, Van Kamp GJ, et al. Effects of processing and storage conditions on amyloid beta (1-42) and tau concentrations in cerebrospinal fluid: implications for use in clinical practice. Clin Chem. 2005;51(1):189-95.

24. Omang $\mathrm{SH}$, Vellar OD. Analytical error due to concentration gradients in frozen and thawed samples. Clin Chim Acta. 1973;49(1):125-6.

25. Willemse E, van Uffelen K, Brix B, Engelborghs S, Vanderstichele $H$, Teunissen C How to handle adsorption of cerebrospinal fluid amyloid beta (1-42) in laboratory practice? Identifying problematic handlings and resolving the issue by use of the Abeta42/Abeta40 ratio. Alzheimers Dement. 2017;13(8):885-92.

26. Berven FS, Kroksveen AC, Berle M, Rajalahti T, Flikka K, Arneberg R, et al. Preanalytical influence on the low molecular weight cerebrospinal fluid proteome. Proteomics Clin Appl. 2007;1 (7):699-711.

27. Rosenling T, Slim CL, Christin C, Coulier L, Shi S, Stoop MP, et al. The effect of preanalytical factors on stability of the proteome and selected metabolites in cerebrospinal fluid (CSF). J Proteome Res. 2009:8(12):5511-22.

28. You JS, Gelfanova V, Knierman MD, Witzmann FA, Wang M, Hale JE. The impact of blood contamination on the proteome of cerebrospinal fluid. Proteomics. 2005;5(1):290-6.

29. Berge G, Lauridsen C, Sando SB, Holder DJ, Moller I, Aasly JO, et al. Effect of Tween-20 on core biomarkers measured in cerebrospinal fluid from patients with Alzheimer's disease, mild cognitive impairment, or healthy control individuals. J Alzheimers Dis. 2016;49(2):493-502.

30. Hu WT, Watts KD, Shaw LM, Howell JC, Trojanowski JQ, Basra S, et al. CSF beta-amyloid 1-42 - what are we measuring in Alzheimer's disease? Ann Clin Transl Neurol. 2015;2(2):131-9.

31. Leitao MJ, Baldeiras I, Herukka SK, Pikkarainen M, Leinonen V, Simonsen AH, et al. Chasing the effects of pre-analytical confounders - a multicenter study on CSF-AD biomarkers. Front Neurol. 2015;6:153.

32. Janelidze S, Pannee J, Mikulskis A, Chiao P, Zetterberg H, Blennow K, et al. Concordance between different amyloid immunoassays and visual amyloid positron emission tomographic assessment. JAMA Neurol. 2017;74(12):1492-501.

33. Janelidze S, Zetterberg H, Mattsson N, Palmqvist S, Vanderstichele H, Lindberg O, et al. CSF Abeta42/Abeta40 and Abeta42/Abeta38 ratios: better diagnostic markers of Alzheimer disease. Ann Clin Transl Neurol. 2016;3(3):154-65.

34. Leuzy A, Chiotis K, Hasselbalch SG, Rinne JO, de Mendonca A, Otto M, et al. Pittsburgh compound B imaging and cerebrospinal fluid amyloid-beta in a multicentre European memory clinic study. Brain. 2016;139(Pt 9):2540-53.

35. Wang MJ, Yi S, Han JY, Park SY, Jang JW, Chun IK, et al. Analysis of cerebrospinal fluid and [11C] PIB PET biomarkers for Alzheimer's disease with updated protocols. J Alzheimers Dis. 2016;52(4):1403-13.

36. Gervaise-Henry C, Watfa G, Albuisson E, Kolodziej A, Dousset B, Olivier JL, et al. Cerebrospinal fluid Abeta42/Abeta40 as a means to limiting tube- and storage-dependent pre-analytical variability in clinical setting. J Alzheimers Dis. 2017;57(2):437-45.

37. Lewczuk P, Beck G, Esselmann H, Bruckmoser R, Zimmermann R, Fiszer M, et al. Effect of sample collection tubes on cerebrospinal fluid concentrations of tau proteins and amyloid beta peptides. Clin Chem. 2006;52(2):332-4.

38. Blennow K, Fredman P, Wallin A, Gottfries CG, Langstrom G, Svennerholm L. Protein analyses in cerebrospinal fluid. I. Influence of concentration gradients for proteins on cerebrospinal fluid/serum albumin ratio. Eur Neurol. 1993;33(2):126-8.

39. Blennow K, Wallin A, Gottfries CG, Mansson JE, Svennerholm L. Concentration gradients for monoamine metabolites in lumbar cerebrospinal fluid. J Neural Transm Park Dis Dement Sect. 1993:5(1):5-15.

40. Mollenhauer B, Trautmann E, Otte B, Ng J, Spreer A, Lange P, et al. alphaSynuclein in human cerebrospinal fluid is principally derived from neurons of the central nervous system. J Neural Transm (Vienna). 2012;119(7):739-46.

\section{Publisher's Note}

Springer Nature remains neutral with regard to jurisdictional claims in published maps and institutional affiliations.

Ready to submit your research? Choose BMC and benefit from:

- fast, convenient online submission

- thorough peer review by experienced researchers in your field

- rapid publication on acceptance

- support for research data, including large and complex data types

- gold Open Access which fosters wider collaboration and increased citations

- maximum visibility for your research: over $100 \mathrm{M}$ website views per year

At BMC, research is always in progress.

Learn more biomedcentral.com/submissions 